\title{
MEMPERMUDAH PENENTUAN REWARD KARYAWAN OJEK ONLINE DENGAN PENERAPAN TEORI FUZZY
}

\author{
${ }^{1}$ Arif Rahman, ${ }^{2}$ Siti Ayu Nurjanah, ${ }^{3}$ Mohammad Mukhlis \\ ${ }^{1}$ IAIN Jember, Jl.Mataram No.1 Mangli, (0331)487550 \\ ${ }^{2}$ IAIN Jember, Jl.Mataram No.1 Mangli, (0331)487550 \\ ${ }^{3}$ IAIN Jember, Jl.Mataram No.1 Mangli, (0331)487550 \\ Email : ${ }_{\text {arifrahman9993@gmail.com. }}$
}

\begin{abstract}
Abstrak
Ojek online adalah penyedia transportasi yang tidak menetap dalam suatu daerah, untuk memesan ojek online cukup hanya melalui internet dan aplikasi kemudian kita menunggu ojek online tersebut datang. Perusahaan ojek online juga mempunyai penilaian terhadap driver-driver nya, juga pelanggan bisa memberikan penilaian terhadap driver ojek online, yaitu dengan pemberian rating bintang, biasanya penilaian pelangan pada driver dilihat dari pelayanan dan kinerja sang driver, hal ini yang menjadi pertimbangan dari perusahaan ojek online itu sendiri untuk memberikan reward kepada driver ojek online. Kami melakukan penelitian tentang penerapan metode fuzzy untuk mempermudah perusahan ojek online memberikan reward kepada karyawannya, Metode fuzzy logic adalah suatu cara untuk memetakan ruang input kedalam ruang output, dalam hal ini variabel input nya terdiri dari beberapa variabel yaitu diantaranya, variabel kinerja, variabel rating pelanggan, dua variabel ini memiliki semesta pembicaraannya masing-masing dimana dari variabel-variabel ini peneliti membuat himpunan fuzzynya, kemudian untuk variabel outputnya ialah pemberian reward kepada driver yang pantas sesuai dengan variabel-variabel input tadi. Tujuan penulisan ini ialah untuk mempermudah perusahaan ojek online untuk menentukan siapa yang pantas untuk menerima reward diantara driver-drivernya. Dan pada akhirnya perusahaan ojek online bisa menentukan siapa yang pantas menerima reward berdasarkan kinerja. Konsistensi, dan pelayanan ojek online pada pelanggannya.
\end{abstract}

Key word : ojek online, fuzzy logic, reward, teori fuzzy, karyawan.

\begin{abstract}
Online motorcycle taxi is a transportation provider that does not live in an area, to order a motorcycle taxi online is enough only through the internet and the application then we wait for the online motorcycle taxi to arrive. Online motorcycle taxi company also has value on its drivers, also customers can give value to the online motorcycle taxi driver, namely by giving a star rating, usually assessing the customer customer discretion in terms of service and driver singing, this is a consideration of the online motorcycle taxi company itself to give gifts to motorcycle taxi drivers online. We conduct research on the application of the fuzzy method to facilitate online motorcycle taxi companies giving gifts to their employees, Fuzzy logic method is a way to map the input space into the output space, in this case the input variable consists of several variables including, among other things, performance variables, customer rating variables, these two variables have their respective universe wherein from these variables the researcher make the fuzzy set, then for the output variable is giving a reward to the appropriate driver in accordance with the input variables earlier. The purpose of this paper is to make it easier for online motorcycle taxi companies to determine who deserves to receive a reward among their drivers. And in the end the online motorcycle taxi company can determine who deserves the reward based on performance. Consistency and online motorcycle taxi service for customers.

Key words: online motorcycle taxi, fuzzy logic, reward, fuzzy theory, employees.
\end{abstract}

\section{PENDAHULUAN.}

Media online atau media siber secara umum adalah saluran komunikasi yang terjadi secara online melalui situs web di internet, baik itu berisi teks, foto, vidio, atau musik. Dengan kata lain, semua jenis saluran komunikasi yang ada di internet adalah media online. 
Sedangkan pengertian media online secara khusus adalah semua yang berhubungan dengan komunikasi massa.

Adapun funsi dan manfaat media online itu sendiri adalah fungsi informal, fungsi sosialisasi, fungsi diskusi dan perdebatan, fungsi pendidikan, fungsi memajukan kebudayaan, fungsi hiburan, dan fungsi integrasi.

Transportasi atau pengangkutan merupakan bidang kegiatan yang sangat penting dalam kehidupan masyarakat indonesia. Menyadari pentingnya peranan transportasi, maka lalu lintas dan angkutan jalan harus ditata dalam suatu sistem transportasi nasional secara terpadu dan mampu mewujudkan ketersediaan jasa transportasi yang sesuai dengan tingkat kebutuhan lalu lintas dan pelayanan angkutan yang tertib, nyaman, cepat, lancar, dan berbiaya murah.

Di era globalisasi saat ini terdapat fenomena ojek yang menyita perhatian masyarakat, yaitu ojek berbasis online (aplikasi), ojek online ini dapat diakses melalui sebuah aplikasi yang mempermudah masyarakat untuk memesan ojek tanpa harus mencari pangkalan ojek, tinggal buka aplikasi dan memesannya.

Ojek online ini juga mempunyai suatu lembaga atau perusahaan yang menaungi pekerja mereka, semisal gojek, grab, dan masih banyak lagi, lembaga ini berfungsi menaungi sekaligus mengontrol kerja aplikasi ojek online yang ada dalam naungannya, pekerjapun bisa dari berbagai pihak masyarakat yang mendaftarkan diri dengan cara yang sudah ditentukan dan juga sudah memenuhi kreteri yang ditentukan perusahaan, semisal umur kendaraan yang akan digunakan untuk bekerja, umur pekerja itu sendiri dan lain sebagainya.

Sedangkan pekerja sendiri itu merupakan elemen yang sangat penting dalam suatu lembaga atau perusahaan, yang nantinya akan menentukan kamajuan sebuah usaha, dalam rangka memberi motivasi kepada karyawan, perlu adanya penghargaan atau reward yang digunakan untuk memotivasi sekaligus menghargai capaian-capaian yang didapatkan oleh pekerja itu sendiri (vita dwi, 2016, 5).

Pengertian dari reward itu sendiri adalah suatu bentuk penghargaan atau imbalan balas jasa yang diberikan kepada seseorang atau kelompok karena telah berperilaku baik, melakukan suatu keunggulan atau prestasi, memberikan suatu sumbangsi, atau berhasil melaksanakan tugas yang diberikan sesuai target yang diterapkan. Istilah reward berasal dari bahasa inggris yang artinya hadiah, penghargaan atau imbalan.

Dalam proses pemilihan reward kepada pekerja, ada beberapa kendala yang dihadapi diantaranya kesulitan memilih karyawan-karyawan yang layak mendapatkan reward dengan 
adanya beberap kriteria sebagai penilaian. Untuk membantu pihak lembaga dalam mengambil keputusan karyawan yang berhak mendapatkan reward diperlukan suatu Sistem pendukung keputusan (yogi, alfiarini, 2017, 107).

Sistem keputusan ini menggunakan metode tsukamoto dengan menerapkan parameter variable data pendukung yang melipuni kinerja, kedisiplinan, kemampuan yang menjadi kriteria dalam penilaian. Pada metode tsukamoto setiap rule diterapkan menggunakan himpunan-himpunan fuzzy dengan fungsi keanggotaan yang konstan, fuzzy tsukamoto adalam metode yang memiliki toleransi pada data dan sangat fleksible. Kelebihan dari metode tsukamoto yaitu bersifat intuatif dan dapat memberikan tanggapan berdasarkan informasi yang bersifat kualitatif, tidak akurat, dan ambigu (dwi vita, 2016).

Teori atau logika fuzzy itu sendiri merupakan logika tegas yang memiliki nilai benar atau salah. Dalam teori logika fuzzy sebuah nilai dianggap benar dan salah secara bersamaan, tergantung pada nilai keanggotaannya. Dan disini ada beberapa alasan mengapa menggunakan teori fuzzi yaitu dapat dibangun dan dikembangkan dengan mudah, ketidak presensian terhadap data dapat di toleril, hubungan data input dan output dari sembarang sistem mudah untuk dilakukan, untuk membangun fuzzy logic pengetahuan atau pengalaman dari pakar dapat dipakai tanpa proses penilaian, secara konvensional fuzzy logic dapat bekerjasama dengan teknik-teknik kendali, serta bahasa alami atau bahasa manusia adalah dasar fuzzy logic.

\section{METODE PENELITIAN}

Jenis penelitian ini merupakan penelitian eksperimen yaitu merancang sistem penilaian berdasarkan fuzzy logic metode tsukamoto dimana dalam metode ini yaitu mengubah input dimana input disini adalah berupa himpunan-himpunan fuzzy untuk mencari nilai tegas output.

\section{Himpunan fuzzy}

Himpunan fuzzy pasti memiliki nilai keanggotaan $(\mu)$ yang berbeda. Pada himpunan fuzzy disini memiliki nilai keanggotaan 0 dan 1 , apabila suatu objek memiliki nilai keanggotaan 0 maka objek itu bukan merupakan anggota dari himpunan, jika memiliki nilai keanggotaan 1 maka objek itu adalah anggota dari himpunan (yogi primadasa, alfiarini, 2017, 108).

Dalam penelitian ini penulis menggunakan tiga variabel yaitu variabel kinerja, variabel rating pelanggan, misalkan pada variabel kinerja memiliki kategori 
MEMUASKAN DAN MENGECEWAKAN dimana memiliki rentang nilainya

masing masing :

MEMUASKAN $: 5 \leq$ puas $\leq 10$

MENGECEWAKAN : kecewa $\leq 5$

Oleh karena itu jika sang driver memiliki nilai kinerja 7 maka kinerjanya termasuk dalam kategori memuaskan, sebaliknya jika memiliki nilai kinerja 4 maka kinerjanya mengecewakan.

2. Fungsi keanggotaan

Fungsi keanggotaan digunakan untuk mencari nilai keanggotaan itu sendiri apakah termasuk dalam 0 atau termasuk dalam 1 dalam hal ini penulis menggunakan fungsi keanggotaan linier dengan dibagi menjadi dua kategori yaitu himpunan linier naik dan himpunan linier turun (yogi primadasa, alfiarini, 2017, 108).

Untuk himpunan linier naik :

$\mu(x) \begin{cases}0 ; & x \leq a \\ \frac{(x-q)}{(b-a)} ; & a \leq x \leq b \\ 1 ; & x \geq b\end{cases}$

Untuk himpunan linier turun :

$\mu(x) \begin{cases}1 ; & x \leq a \\ \frac{(b-x)}{(b-a)} ; & a \leq x \leq b \\ 0 ; & x \geq b\end{cases}$

\section{HASIL DAN PEMBAHASAN}

Pada proses penelitian ini yang menjadi acuan sebagai pantas atau tidaknya seorang driver menerima reward dari pelanggan ialah dari variabel input, sedangkan reward itu sendiri adalah sebagai variabel outputnya. Variabel inputnya sendiri ada dua yitu ada variabel kinerja sang driver dimana menggambarkan hasil kerja sang driver selama satu bulan dan yang kedua adalah variabel rating dari pelanggan nah pada variabel ini mencakup pelayanan, kedisiplinan sang gojek dan keramhan drivernya sudah termasuk dalam rating pelanggan.

Tabel 1.1. Varianel input dan nilai fuzzy

\begin{tabular}{|c|l|c|}
\hline Variabel & \multicolumn{1}{|c|}{ Himpunan } & Nilai Fuzzy \\
\hline \multirow{2}{*}{ Varibel kinerja } & Memuaskan & \multirow{2}{*}{$10-30$} \\
\cline { 2 - 3 } & Mengecewakan & \\
\hline
\end{tabular}

ARITMATIKA, Vol. 1, No. 1, Juni 2020. 


\begin{tabular}{|c|l|c|}
$\begin{array}{c}\text { variabel rating } \\
\text { pelanggan }\end{array}$ & Tinggi & \\
\cline { 2 - 2 } & Rendah & \\
\hline
\end{tabular}

Tabel 1.2. variabel output dan nilai fuzzy

\begin{tabular}{|c|l|l|}
\hline Variabel output & \multicolumn{1}{|c|}{ Himpunan } & Nilai Fuzzy \\
\hline \multirow{2}{*}{ reward } & Dapat & \multirow{2}{*}{$20-60$} \\
\cline { 2 - 2 } & Tidaj dapat & \\
\hline
\end{tabular}

Perhatikan kedua tabel diatas pada tabel 1.1 adalah tabel variabel input dengan rentangan nilai fuzzynya yaitu ialah 10-30 untuk variabel kinerja dan untuk variabel rating pelanggan ialah 10-30. Dan pada tabel 1.2 adalah variabel output dimana pada variabel output adalah reward itu sendiri

1. Fuzzy Inference System Rule

a. IF variabel kinerja memuaskan dan variabel rating pelanggan tinggi THEN driver dapat reward.

b. IF variabel kinerja mengecewakan dan variabel rating pelanggan tinggi THEN driver tidak dapat reward.

c. IF variabel kinerja memuaskan dan variabel rating pelanggan rendah THEN driver tidak dapat reward.

d. IF variabel kinerja mengecewakan dan variabel rating pelanggan rendah THEN driver tidak dapat reward.

2. Fungsi keanggotaan variabel

Pada penelitian ini variabel dibagi menjadi dua yaitu input dan output dimana input sendiri dibagi menjadi variabel kinerja dan variabel rating pelanggan, sedangkan outputnya yaitu reward.

a. Variabel kinerja

Variabel kinerja sendiri dibagi menjadi dua kategori yaitu kategori memuaskan dan mengecewakan. Yang memiliki fungsi keanggotaan seperti dibawah ini. 


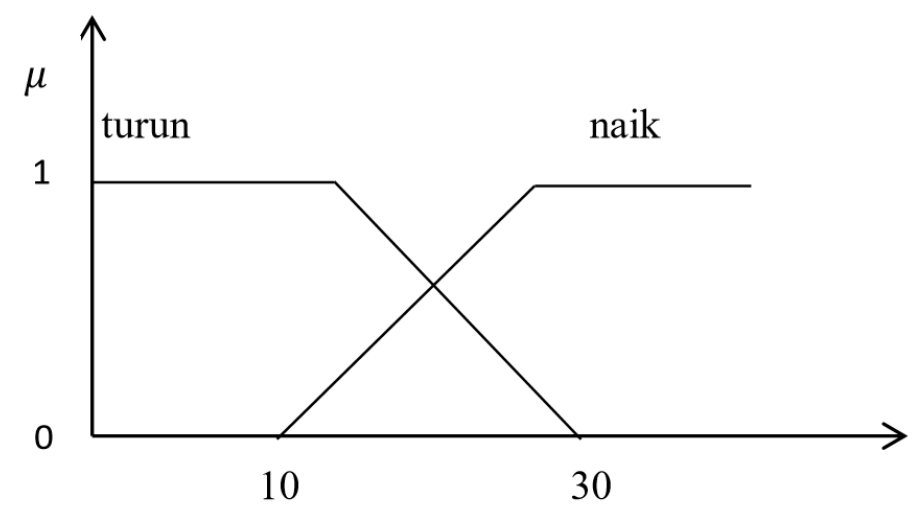

b. Variabel rating pelanggan

Variabel rating pelanggan terdiri menjadi dua kategori yaitu tinggi dan rendah yang memiliki fungsi keanggotaan seperti pada gambar di bawah ini :

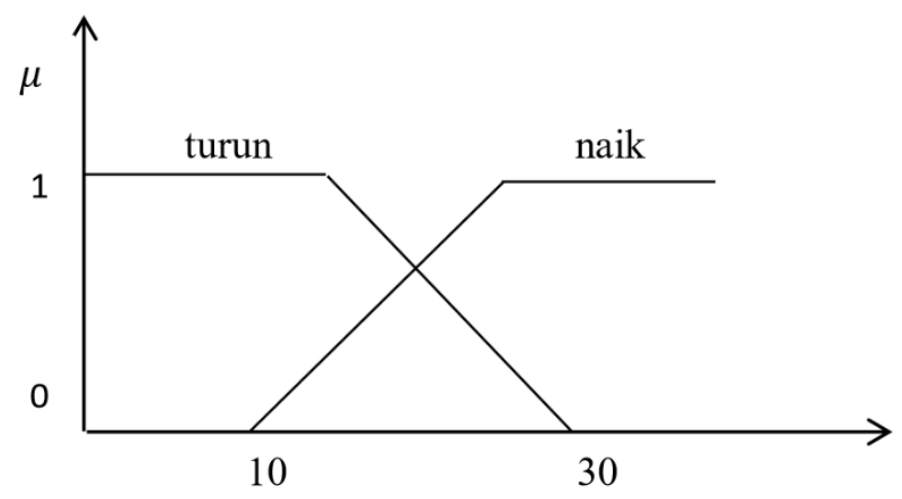

c. Variabel reward

Variabel reward sendiri di bagi menjadi dua himpunan yaitu dapat dan tidak dapat, yang memiliki fungsi keanggotaan seperti dibawah ini:

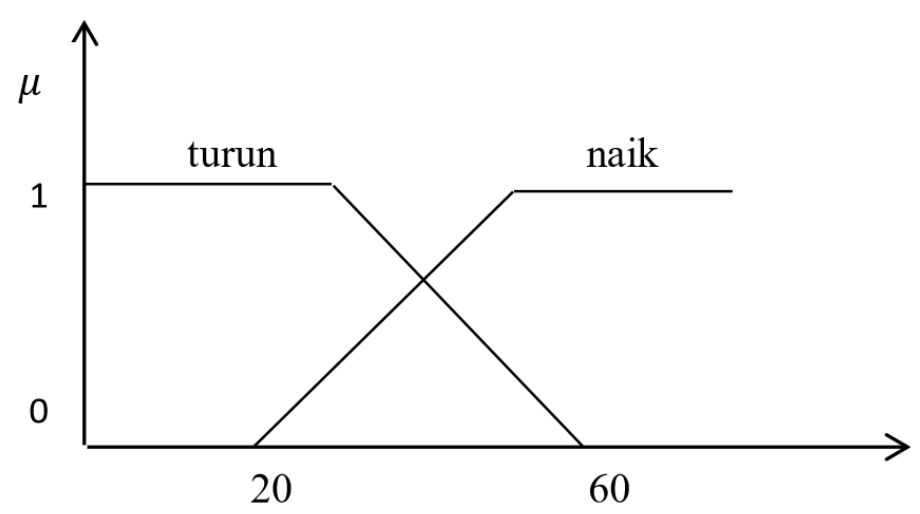

Dari fungsi keanggotaan variabel-variabel input dan variabel output penulis melakukan uji data dengan variabel-variabel yang ditentukan, data berikut adalah kinerja seorang ojek online dengan nilai fuzzy nya 1-20 dan nilai variabel ratingnya ialah 1-5 
Tabel 1.3. Data beberapa kinerja dan rating pelanggan terhadap ojek online

\begin{tabular}{|c|c|c|}
\hline Ojek online & kinerja & $\begin{array}{c}\text { Rating } \\
\text { pelanggan }\end{array}$ \\
\hline A & 26 & 25 \\
\hline B & 18 & 15 \\
\hline C & 12 & 12 \\
\hline
\end{tabular}

Fungsi keanggotaan dari variabel kinerja A adalah sebagai berikut

$$
\begin{aligned}
& \mu_{\text {naik }}(\mathrm{x}):\left\{\begin{array}{c}
0, \mathrm{x} \leq 10 \\
\frac{\mathrm{x}-10}{20}, 10 \leq \mathrm{x} \leq 30 \\
1, \mathrm{x} \geq 30
\end{array}\right. \\
& \mu_{\text {turun }}(\mathrm{x}):\left\{\begin{array}{c}
1, \mathrm{x} \leq 10 \\
\frac{30-\mathrm{x}}{20}, 10 \leq \mathrm{x} \leq 30 \\
0, \mathrm{x} \geq 30
\end{array}\right.
\end{aligned}
$$

Kemudian untuk mencari nilai keanggotaan dari variabel kinerja A dapat dicari dengan cara sebagai berikut :

$$
\begin{gathered}
\mu_{\text {kinerja mengecewakan }}(26)=\frac{30-\mathrm{x}}{20} \\
=\frac{4}{20} \\
=0,2 \\
\mu_{\text {kinerja memuaskan }(26)}=\frac{26-10}{20} \\
=\frac{16}{20} \\
=0,8
\end{gathered}
$$

Kemudian fungsi keanggotaan untuk variabel rating pelanggan untuk A adalah sebagai berikut :

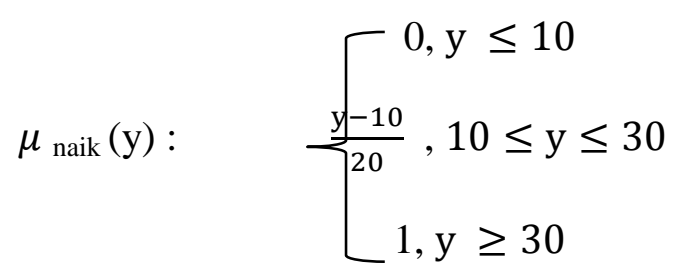


$\mu_{\text {turun }}(\mathrm{y}):\left\{\begin{array}{l}1, \mathrm{y} \leq 10 \\ \frac{30-\mathrm{y}}{20}, 10 \leq \mathrm{y} \leq 30 \\ 0, \mathrm{y} \geq 30\end{array}\right.$

Nilai keanggotaan dari variabel rating pelanggan bagi driver A dapat di ketahui dengan :

$$
\begin{array}{r}
\mu_{\text {rating Rendah }}(25)=\frac{30-25}{20} \\
=\frac{5}{20} \\
=0,25 \\
\mu_{\text {rating Tinggi }}(25)=\frac{25-10}{20} \\
=\frac{15}{20} \\
=0,75
\end{array}
$$

Lalu yang terakhir adalah fungsi keanggotaan dari variabel output yaitu reward dalam hal ini variabel reward dibagi menjadi dua himpunan yaitu dapat dan tidak dapat

$$
\begin{aligned}
& \mu_{\text {tidakdapat }(\mathrm{z}):: \frac{60-\mathrm{z}}{40}}\left[\begin{array}{r}
1, \mathrm{z} \leq 20 \\
20 \leq \mathrm{z} \leq 60 \\
0, \mathrm{z} \geq 60
\end{array}\right.
\end{aligned}
$$

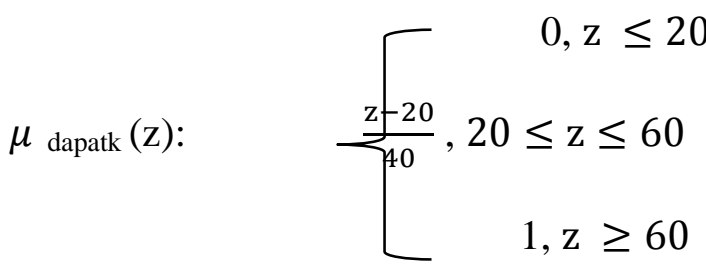

Untuk mencari nilai keanggotaan himpunan Tidak Dapat dan DAPAT dari variable reward, maka harus dicari nilai z nya terlebih dahulu dengan cara sebagai berikut: mencari nilai z dapat dilakukan dengan menggunakan fungsi MIN pada aplikasi fungsi. Digunakanlah yang namanya aturan inferensi.

Berikut adalah aturan inferensi yang sudah ditentukan :

[R1]. IF variabel kinerja memuaskan dan variabel rating pelanggan tinggi THEN driver dapat reward.

$\alpha$-predikat $=\mu_{\text {kinerja memuaskan }} \cap_{\text {rating pelanggan tinggi }}$ 


$$
\begin{aligned}
& =\min \left(\mu_{\text {kinerja memuaskan }}[26], \mu_{\text {rating pelanggan tinggi }}[25]\right) \\
& =\min (0,8 ; 0,75) \\
& =0,75
\end{aligned}
$$

Sehingga kita dapat mengetahui himpunan reward "DAPAT" nya adalah :

$\frac{\mathrm{z}-20}{40}=0,75$

$z-20=0,75 \times 40$

$z_{1}=30+20=50$

[R2].IF variabel kinerja mengecewakan dan variabel rating pelanggan tinggi THEN driver tidak dapat reward.

$\alpha$-predikat $=\mu_{\text {kinerja mengecewakan }} \cap$ rating pelanggan tinggi

$$
\begin{aligned}
& =\min \left(\mu_{\text {kinerja mengecewakan }}[26], \mu_{\text {rating pelanggan tinggi }}[25]\right) \\
& =\min (0,2 ; 0,75) \\
& =0,2
\end{aligned}
$$

Sehingga kita dapat mengetahui himpunan reward "TIDAK DAPAT" nya adalah :

$\frac{60-\mathrm{z}}{40}=0,2$

$60-z=0,2 \times 40$

$\mathrm{Z}_{2=60-8=52}$

$\mathrm{R}$ [3].IF variabel kinerja memuaskan dan variabel rating pelanggan rendah THEN driver tidak dapat reward.

$\alpha$-predikat $=\mu_{\text {kinerja memuaskan }} \cap$ rating pelanggan rendah

$$
\begin{aligned}
& =\min \left(\mu_{\text {kinerja mengecewakan }}[26], \mu_{\text {rating pelanggan rendah }}[25]\right) \\
& =\min (0,8 ; 0,25) \\
& =0,25
\end{aligned}
$$

Sehingga kita dapat mengetahui himpunan reward "TIDAK DAPAT" nya adalah :

$$
\begin{aligned}
& \frac{60-z}{40}=0,25 \\
& 60-z=0,25 \times 40 \\
& Z_{3}=60-10=50
\end{aligned}
$$

$\mathrm{R}[4]$.IF variabel kinerja mengecewakan dan variabel rating pelanggan rendah THEN driver tidak dapat reward. 


$$
\begin{aligned}
\alpha \text {-predikat } & =\mu_{\text {kinerja mengecewakan }} \cap_{\text {rating pelanggan rendah }} \\
& =\min \left(\mu_{\text {kinerja mengecewakan }}[26], \mu_{\text {rating pelanggan rendah }}[25]\right) \\
& =\min (0,2 ; 0,25) \\
& =0,2
\end{aligned}
$$

Sehingga kita dapat mengetahui himpunan reward "TIDAK DAPAT” nya adalah :

$\frac{60-\mathrm{z}}{40}=0,2$

$60-z=0,2 \times 40$

$Z_{4=60-8=52}$

setelah semua nilai $z$ diketahui selanjutnya kita mencari nilai output crispnya dengan cara sebagai berikut

$\mathrm{Z}=\frac{(\alpha 1 . z 1)+(\alpha 2 . z 2)+(\alpha 3 . z 3)+(\alpha 4 . z 4)}{\alpha 1+\alpha 2+\alpha 3+\alpha 4}$

$Z=\frac{0.75 \cdot 50+0,2 \cdot 52+0,25 \cdot 50+0,2 \cdot 52}{0,75+0,2+0,25+0,2}$

$Z=\frac{70,8}{1,4}=50,6$

Maka kesimpulan nya nilai variabel output reward driver A dengan kinerja 26 dan rating pelanggan 25 menghasilkan nilai output crispnya ialah 50,6 maka driver A benar pantas mendapatkan reward dari perusahaan.

Jadi hasil perhitungan secara keseluruhan dari data ini adalah sebagai berikut yang tercantum pada tabel dibawah ini.

Tabel 1.4. hasil perhitungan

\begin{tabular}{|c|c|c|c|c|}
\hline & Kinerja & $\begin{array}{c}\text { Rating } \\
\text { pelanggan }\end{array}$ & Nilai & kategori \\
\hline A & 26 & 25 & 50,6 & Dapat \\
\hline B & 18 & 15 & 39,4 & Dapat \\
\hline C & 12 & 12 & 26,6 & Tidak dapat \\
\hline
\end{tabular}

ARITMATIKA, Vol. 1, No. 1, Juni 2020. 


\section{KESIMPULAN}

Berdasarkan hasil penelitian tentang implementasi atau penerapan metode fuzzy tsukamoto untuk proses penentuan reward karyawan ojek online yang telah dirancang, didapat kesimpulan yaitu dengan adanya aplikasi ini telah mampu memudahkan bagi perusahaan yang menaungi ojek online itu sendiri dalam pengambilan keputusan untuk menentukan reward karyawan.

\section{DAFTAR PUSTAKA}

\section{Books:}

Abdurrahman Ginanjar. 2011. "PENERAPAN METODE TSUKAMOTO (LOGIKA FUZZY) DALAM SISTEM PENDUKUNG KEPUTUSAN UNTUK MENENTUKAN JUMLAH PRODUKSI BARANG BERDASARKAN DATA PERSEDIAAN DAN JUMLAH PERMINTAAN". Fakultas Matematika Dan Ilmu Pengetahuan Alam. Universitas Negeri Yogyakarta. Yogyakarta.

Dwi Vita. 2016. "PENERAPAN FUZZY TSUKAMOTO PADA APLIKASI PENGGAJIAN KARYAWAN". Fakultas Teknik. Universitas Nusantara Persatuan Guru Republik Indonesia. Kediri.

Komariyah, Yunus, Dkk. 2017. "LOGIKA FUZZY DALAM SISTEM PENGAMBILAN KEPUTUSAN PENERIMAAN BEASISWA". Fakultas teknik. Universitas Majalengka. Majalengka.

Krisma, Malikatul, Dkk. 2017. "PENERAPAN LOGIKA FUZZY DALAM MENENTUKAN HARGA JUAL JAMUR TIRAM PUTIH BERDASARKAN KUALITAS DAN PERMINTAAN KONSUMEN". Teknik Informatika: Universitas Nusantara PGRI. Kediri.

\section{Online journal:}

Maryaningsih, Siswanto, Mesterjon. 2013 "METODE LOGIKA FUZZY TSUKAMOTO DALAM SISTEM PENGAMBILAN KEPUTUSAN PENERIMAAN BEASISWA". Vol. 9 No. 1. 9 Mei 2020.

Nasir, Supriyanto. 2017. "ANALISIS FUZZY LOGIC MENENTUKAN PEMILIHAN MOTOR HONDA DENGAN METODE MAMDANI". Vol. 3 NO. 2. 9 Mei 2020.

Syahnandar, Rahmat, Dkk. 2017. "IMPLEMENTASI FUZZY LOGIC PENENTUAN KELAYAKAN KARYAWAN MENDAPATKAN REWARD DITOKO ROTI MENGGUNAKAN METODE TSUKAMOTO". Vol. 10 No. 2. 1 april 2020.

Yogi, Alfiarina. 2017. "FUZZY INFERENCE SYSTEM TSUKAMOTO PENENTUAN NILAI RIWARD YANG DITERIMA KARYAWAN". Vol. 4 No. 2. 1 april 2020. 
Yusli, Irsan. 2017. "LOGIKA FUZZY MENENTUKAN JUMLAH PRODUKSI BERDASARKAN PERSEDIAAN DAN JUMLAH PERMINTAAN". Vol. 3 No. 2.9 mei 2020.

Theses, Dissertation:

Laras, Irfan, Jumadi. 2017. "ANALISIS PERBANDINGAN LOGIC FUZZY METODE TSUKAMOTO, SUGENO, DAN MAMDANI (STUDI KASUS ; PREDIKSI JUMLAH PENDAFTAR MAHASISWA BARU FAKULTAS SAINS DAN TEKNOLOGI UNIVERSITAS ISLAM NEGERI SUNAN GUNUNGJATI BANDUNG). Fakultas Sains dan Teknologi. Universitas Islam Negeri Sunan Gunungjati Bandung. Bandung. 